\title{
OS MIGRANTES NA IMPRENSA ALEMÃ
}

\author{
Luisa Deponti * \\ - Traduzido do italiano por \\ Dirceu Cutti e Margherita Bonassi -
}

\section{Algumas Considerações Gerais}

A sociedade atual caracteriza-se cada vez mais por um rápido desenvolvimento da assim chamada "sociedade da informação", na qual os meios de comunicação de massa adquirem um papel central na sua função de "observadores" e de "construtores" de realidade social, tanto assim que as interpretações que esses dão aos acontecimentos não só se tornaram indispensáveis para a compreensão do mundo real, como também repercutem sobre este modificando-o. A informação jornalística possui, portanto, grande responsabilidade quer em favorecer, quer em tornar mais conflitante o inevitável processo de encontro e de integração entre diferentes etnias no interior da sociedade.

$\mathrm{Na}$ Alemanha, a presença de diversas línguas, culturas e religiões deve-se, sobretudo, aos processos migratórios, ocorridos em fases sucessivas a partir dos anos 50 do século passado. Vários estudos ocuparam-se, ao longo dos anos 90 , em analisar a imagem que os veículos de informação da Alemanha, no seu conjunto, fornecem sobre a imigração. Tal representação vem definida como uma "construção de realidade" que possui características próprias, em parte autônomas em relação à realidade dos fatos. As redações realizam, de fato, em cada âmbito temático, uma seleção dos acontecimentos do mundo externo e uma reelaboração própria em forma de notícias, de acordo com princípios próprios do sistema jornalístico (como, por exemplo, o critério da notícia que se impõe); o resultado de tal procedimento não é uma imagem refletida da realidade, mas uma nova versão que apresenta distorções segundo tendências bem definidas (Ruhrmann, 1996).

No que concerne ao tema "a sociedade alemã e os imigrantes", prevalecem, em geral, os critérios da negatividade e do impactante dos acontecimentos reportados, além do que o sistema informativo depende fortemente, na acentuação dos argumentos, daquilo que a esfera política coloca no centro da sua atenção, bem como do debate público. Não se pode afirmar que os jornalistas agem com uma postura conscientemente hostil com relação aos estrangeiros. É o próprio sistema informativo que, guiado pelos critérios de atualidade e do sensacionalismo, acaba por colocar em primeiro plano os aspectos negativos e extraordinários que dizem respeito à cotidiana e positiva convivência entre nacionais e imigrantes (Meier-Braun, 2001: 59-68).

Naturalmente, os meios de comunicação têm o dever de informar sobre os problemas inerentes às migrações. Todavia, o risco é o de apresentar somente alguns aspectos da realidade, em geral de modo simplista, sem remeter a informações mais completas que permitam aos ouvintes compreender mais profundamente a complexidade do fenômeno migratório.

Como têm demonstrado alguns estudos (Gerhard, 1992: 165; Bartelt, 1993: 35-38; Jäger, 1993), também a linguagem utilizada pelos veículos de comunicação, ao referir-se aos imigrantes, não está isenta de elementos negativos. $\mathrm{Na}$ informação jornalística desenvolveu-se uma série de imagens recorrentes que reforçam preconceitos e ressentimentos no interior da população. Os símbolos que estão em jogo podem ser fotografias, montagens, caricaturas, como também metáforas lingüísticas, imediatamente compreensíveis a todos e por isso mesmo ainda mais eficazes. São usados pelos jornalistas sem uma intenção 'xenófoba', mas muito mais por sua mediação na comunicação com o público.

A metáfora mais comum é a da inundação; a imigração vista como uma ameaça. Aparecem também como variantes maré, ondas, corrente, fluxo. Desta imagem, passa-se à idéia 'militar'de invasão, de assalto e de assédio, dos fluxos migratórios como forças de pressão e bombas-relógio. Também fotos e vinhetas reproduzem este esquema: multidões chegando, intermináveis filas de estrangeiros nas fronteiras ou em frente aos guichês dos órgãos públicos. A Alemanha transformase, portanto, no barco que corre o risco de afundar, a fortaleza assediada ou a ilha de paz ameaçada de invasão.

Freqüentemente, as metáforas não são criadas pelos jornalistas, mas são colocadas em circulação pelos próprios políticos através de estratégias típicas deles diante da opinião pública. Os 
órgãos de informação, que dedicam a maior parte do seu espaço às elites políticas, transformam-se, voluntariamente ou não, em caixas de ressonância, por diversas formas, da instrumentalização do fenômeno migratório (Wichert, 1997).

Para melhor entender a evolução do discurso da mídia sobre a imigração na Alemanha nos últimos dez anos, convém percorrer os principais acontecimentos deste período e observar quais temas são majoritariamente abordados pelos meios de comunicação.

\section{O período 1990-1993: A imigração dramaticamente no centro das atenções}

A queda do Muro de Berlim (9 de novembro de 1989) e a Reunificação das duas Alemanhas (3 de outubro de 1990) representam uma guinada de grande porte histórico para a República Federal, bem como para toda a Europa. Igualmente, no âmbito da imigração no território alemão, estas datas constituem um momento de transição muito importante, que conduz ao terceiro grande processo de integração de estrangeiros após o término da Segunda Guerra Mundial.

A situação migratória aparece, neste período, antes que mais nada, complexa (Bade, 1994: 55-65). A maioria da população estrangeira (que somava em 1990 um total de 5.342 .500 pessoas) é formada pelos chamados Gastarbeiter (trabalhadores-hóspedes), chegados sobretudo nos anos de 1960-70 como mão-de-obra necessária ao desenvolvimento industrial, e pelos seus familiares e descendentes, já de segunda ou terceira geração. Os grupos mais representativos são os turcos, italianos, iugoslavos e gregos. Estes, contrariamente às expectativas de muitos políticos e da opinião pública, não se comportam como 'hóspedes' que chegam e depois de um tempo vão-se embora; um número significativo destes imigrantes se estabelece definitiva- mente na República Federal. A Alemanha transforma-se, assim, de fato, em um país de imigração, sem que isso seja reconhecido oficialmente pelos governos que se sucedem de mandato em mandato. Esta falta de reconhecimento provoca déficits na política de integração e, consequentemente, graves descompassos sociais entre a população imigrada, também em virtude da conjuntura econômica desfavorável desses anos (Meier-Braun, 1995).

Desde o final dos anos $80 \mathrm{e}$ ao longo da década de 90 , torna-se maciço o afluxo de Aussiedler da Europa Oriental - especialmente da ex-União Soviética -, os quais constituem, na Alemanha reunificada, o segundo grupo mais numeroso de imigrantes. Trata-se de cidadãos da Europa do Leste, descendentes de alemães emigrados para os países orientais e sub-orientais da Europa ao longo de três séculos de história. Com base na Constituição, estes obtêm a cidadania alemã, todavia, sua integração sócio-cultural assemelha-se em tudo a qualquer outro processo de imigração, nos quais emergem grandes diferenças de mentalidade e não raro dificuldades com a língua.

No início dos anos 90 também ganha forte impulso o ingresso de refugiados provenientes da Europa do Leste (principalmente em virtude da guerra dos Bálcãs) e dos países do chamado Terceiro Mundo, constituindo esses o terceiro grupo mais representativo entre os imigrantes. O caminho pelo qual ingressam na Alemanha é o do direito de asilo político assegurado pela Constituição em seu artigo $16^{\circ}$, bem como pela Convenção de Genebra para os refugiados.

Assim sendo, entre o ano de 1990 e 1993, o número de estrangeiros na Alemanha passa de 5.342 .500 para 6.878 .100 , o equivalente a $8,5 \%$ do total da população (Schmalz-Jakobser, 1995).

Os anos imediatamente subseqüentes à reunificação alemã caracterizam-se como um período de fortes tensões e de insegurança, conseqüência direta das dificuldades de integração entre as duas Alemanhas e da própria crise econômica. Os maiores problemas deste período de transição evidenciam-se, obviamente, no Leste. Já em 1991 manifestam-se entre os novos Länder (Estados), atitudes de clara rejeição, com atos de violência nos confrontos com os estrangeiros. Logo a seguir, o mesmo acontece no Oeste. E muito rapidamente toma conta da opinião pública a discussão sobre o crescimento de uma nova violência xenófoba (Bade, 1994: 55-65).

Os meios de comunicação nacionais e internacionais divulgam amplamente as imagens dos fatos mais chocantes. Tanto na Alemanha, quanto no exterior, cresce o temor de um ressurgimento do nazismo. Entretanto, várias características desta explosão de violência, demonstram não ser tanto o resultado de convicções políticas de caráter neonazista e que tampouco é um fenômeno restrito à Alemanha, tanto assim que atitudes semelhantes passaram a ocorrer em outros países da Europa.

Ainda durante os primeiros anos da década de 90 , a população alemã deparase com sérios problemas em relação ao seu próprio futuro. A opinião pública mostra-se particularmente sensível, sobretudo num momento em que a pressão migratória Leste-Oeste e SulNorte aumenta (Fijalkowski, 1996: 35).

Como reação diante de acontecimentos de caráter extraordinário, os meios de comunicação dramatizam a situação, criando um cenário de um país à beira da crise. Até o final de 1993, falase, sobretudo, do crescente número de refugiados que, segundo muitos, abusam do generoso direito de asilo facultado pela Alemanha. Há quem propõe, inclusive, mudanças no sentido restritivo no artigo $16^{\circ}$ da Constituição. As atenções concentram-se, pois, nesta situação controvertida. Para muitos subsiste a impressão que o Estado tenha em mãos uma fácil solução para todos os problemas, inclusive fazendo frente 
à violência xenófoba (Bade, 1995-96: 96). Os anos de 1991-93 caracterizamse por contínuas trocas de acusações entre a maioria governista (cristãosdemocratas e liberais) e a oposição no que diz respeito às opções feitas quanto ao direito de asilo. Isso fomenta nos meios de comunicação o interesse pelo assunto, o qual, dessa forma, acaba se transformando num dos problemas mais sentidos também pela população. E, num contexto em que ocorrem vários turnos eleitorais regionais, a instrumentalização política do tema só faz aumentar.

Diante do número crescente de pedidos de asilo durante o ano de 1992 , os partidos da maioria e da oposição põem-se de acordo para introduzir mudanças na Constituição, o que vem a ocorrer no ano de 1993 (Meier-Braun, 1995: 19). A justificativa apresentada é simples: a xenofobia propaga-se em virtude do número excessivo de solicitações de asilo. E, ademais, os solicitantes não são na verdade perseguidos políticos, mas sim migrantes econômicos que se utilizam indevidamente do direito de asilo para estabelecer-se na Alemanha.

Durante este período, os meios de comunicação, salvo algumas exceções, não assumem uma atitude crítica nos confrontos das decisões dos partidos, mas se transformam em caixa de ressonância das tomadas de posição da elite política, deixando totalmente de lado a complexidade do fenômeno migratório e dando forte ênfase à discussão sobre a reforma da lei de asilo.

\section{4-1998: período do imobilismo político}

No transcorrer do ano de 1993, o efervescente debate vai esfriando, isso porque as alterações introduzidas no artigo $16^{\circ}$ da Constituição parecem propiciar o resultado esperado de uma diminuição no número dos que procuram asilo na Alemanha. Após as manifestações xenófobas do começo dos anos 90, em 1994 constata-se uma espécie de pausa em torno da discussão da questão migratória (Meier-Braun, 1995, 1996). De fato, as próprias orientações internas dos partidos, por ocasião do super-ano eleitoral de 1994 com diversos pleitos eleitorais previstos em nível regional e nacional -, eram no sentido de que, durante as campanhas, não se tocasse no assunto. Os políticos estavam temerosos de que, evocando "feridas abertas", pudessem ressurgir os conflitos em maior escala, diminuídos nesse meio tempo graças às firmes intervenções da polícia, sobretudo contra as organizações da direita. À fase crítica do começo dos anos 90, segue-se, portanto, um silencioso recuo da esfera política e dos meios de comunicação no que concerne aos delicados temas que envolvem a presença das minorias, configurando a passagem de uma postura de alarmismo para um tratamento mais natural da questão. Outros temas passam, então, a figurar na pauta do dia: o desemprego em massa, as reformas no campo dos direitos sociais e a corrida em direção ao caminho da integração econômica européia.

Nesse intervalo, porém, o número dos estrangeiros continua crescendo, e atinge em 1997 a casa dos 7,6 milhões de pessoas $(8,9 \%$ da população). Na verdade, as cifras dos que ingressam solicitando asilo e dos Aussiedler decaem significativamente em comparação aos primeiros anos da década de 90 . Há, pois, que se considerar que o aumento na contabilização do número dos estrangeiros deve-se ao processo de reunificação familiar, bem como do crescimento vegetativo dos descendentes de imigrantes nascidos na Alemanha, pois, em virtude do direito de cidadania alemã fundar-se no princípio do "ius sanguinis", os mesmos, ao nascer, não adquirem, automaticamente, a cidadania alemã (Beck, 2001). Por outro lado, é difícil enumerar quantos são os migrantes que vivem na clandestinidade na República Federal (provavelmente centenas de milhares), necessários à economia informal e totalmente desprovidos de proteção diante das mais diferentes formas de exploração. O número destes, sem dúvida, cresceu após as restrições impostas ao direito de asilo, que para muitos representava o único caminho possível para ingressar legalmente no país.

As temáticas da imigração e da convivência multicultural, que foram jogadas para um segundo plano, ressurgem nos meios de comunicação e, mais uma vez, tendo como foco central os critérios da negatividade e do extraordinário. Entre os anos de 1995 e 1998 emerge com força a questão da segurança interna da nação: fala-se dos estrangeiros envolvidos com a criminalidade, da importação de conflitos políticos, étnicos e religiosos dos países de origem pela ação de alguns grupos extremistas (como, por exemplo, o conflito curdo-turco) e, enfim, do encontro/desencontro entre culturas tão diversas, em particular a do islamismo versus o mundo ocidental. Mais uma vez os meios de comunicação agem privilegiando os aspectos negativos e problemáticos em prejuízo do bom andamento e da convivência pacífica e enriquecedora entre cidadãos nacionais e imigrantes (Meier-Braun, 2001: 59-68).

A demora na solução dos problemas relativos à integração deixa aberto, efetivamente, o caminho para o surgimento de novas questões, que recaem até mesmo sobre os imigrantes em situação estável na República Federal. Internamente, o índice de desemprego é muito elevado; entre os jovens de segunda e terceira geração verificam-se ainda muitas dificuldades de inserção nas áreas educacional e social. Os meios de comunicação realçam o estranhamento existente entre a comunidade turca e a sociedade alemã, constatação esta que se transforma num dos principais temas do debate imigratório ao longo dos anos 1995-98, juntamente com a preocupação de um alastramento dos movimentos fundamentalistas islâmicos e 
nacionalistas, até mesmo entre os filhos de imigrantes nascidos e criados na República Federal: um sinal evidente de que o não favorecimento de um processo de integração e, portanto, o seu retardamento, propicia um aumento dos conflitos. Nesse contexto, a comunidade turca aparece, via de regra, como a mais referida pelos meios de comunicação, em virtude, primeiramente, de sua superioridade numérica (aproximadamente dois milhões de pessoas), mas também pelo maior distanciamento cultural-religioso em relação à sociedade anfitriã (Münz, 1999: 50-51).

Outro cavalo de batalha dos debates políticos e, consequentemente, da própria imprensa, é a divulgação dos delitos cometidos pelos imigrantes. Nos noticiários, nos quais freqüentemente aparece citada a nacionalidade de origem dos envolvidos criminalmente, bem como a divulgação das estatísticas da polícia, colocam em evidência um forte envolvimento dos estrangeiros com a delinqüência, criando medos e preconceitos, isto porque os dados acabam sendo instrumentalizados por diversos partidos, quer da maioria governișta, quer da oposição. Várias vozes se levantam para dar uma interpretação mais correta e menos sensacionalista aos números difundidos pelos meios de comunicação (Geibler, 1997: 517-518), mas, efetivamente, cada vez mais a opinião pública insiste em associar o tema da criminalidade com a presença dos estrangeiros.

Se bem que em proporções muito mais reduzidas quando o tema em questão é segurança, aparecem especialmente na imprensa de maior credibilidade - análises que focam o verdadeiro problema da situação migratória, qual seja: o fato de que a Alemanha precisa reconhecer-se como país de imigração para poder, antes de mais nada, tomar consciência da grande contribuição social, econômica e cultural aportada pelos imigrantes e, a partir disso, elaborar uma política mais ampla e propositiva, que possibilite uma melhor integração daqueles que há anos residem no país, bem como de seus filhos ali nascidos e criados, e poder traçar uma regulamentação para os novos movimentos migratórios (Hailbronner, 1997).

O governo (ainda comandado pela CDU/CSU e liberais) julga prematuro o momento para abordar um tema tão impopular como o da imigração. A opção de não intervir neste campo com uma legislação mais aberta decorre de uma mistificação, veiculada também pela imprensa mais conservadora. Diante da opinião pública, preocupada com o crescimento do desemprego, aparece como embaraçosa a idéia de uma política de promoção das minorias há tempo estabelecidas no país, com a idéia de uma abertura sem restrições nas fronteiras para com os novos fluxos imigratórios. No momento, portanto, toda tentativa de reformulação na legislação dos estrangeiros é barrada.

\section{8-2001: Novo governo, nova política migratória?}

As eleições do Parlamento Federal Alemão, transcorridas em 27 de setembro de 1998 , sinalizam para o fim da era do Chanceler Helmut Kohl. A maioria que $\mathrm{o}$ apoiava foi substituída por uma nova coalizão de governo formada pelo partido social-democrata (SPD) e pelos verdes, sob a liderança de Gerhard Schröder.

Esta mudança representa também o retorno da temática migratória no âmbito do debate político. Os dois partidos vitoriosos nas eleições, efetivamente entram em acordo, em seus programas, para a realização da reforma do direito de cidadania, visando possibilitar a naturalização de uma parcela da população estrangeira. Sobressai-se, então, com mais insistência nos veículos de comunicação, a voz daqueles que sustentam a necessidade da Alemanha declarar-se "país de imigração" e, conseqüentemente, de criar uma lei voltada para o controle dos fluxos migratórios e sua regulamentação, com o objetivo de aproveitamento dos efeitos positivos no plano econômico, demográfico e cultural e de limitação, ao invés, para os casos potenciais de conflitos e desestabilização da segurança interna do país e da convivência multicultural (Münz, 1998).

Também os social-democratas, agora no governo, movem-se com grande cautela no campo das migrações para não perder consensos. Semelhante postura ganha força depois que, com a aprovação dos direitos de cidadania, desencadeia-se a contra-ofensiva da CDU/CSU que se conclui com uma solene derrota eleitoral dos socialdemocratas nas regiões de Hessen já nos primeiros meses de 1999.

Persiste, portanto, nesta fase, a perigosa tendência dos partidos em instrumentalizar o tema da imigração para os próprios interesses imediatos. Desta maneira propaga-se na opinião pública uma imagem, não raro, distorcida da realidade, favorecendo a insegurança e o temor antes que uma maior compreensão.

Por outro lado, pode-se observar positivamente que nas discussões tomam parte também vozes externas ao mundo político, tais como: estudiosos da migração, demógrafos, especialistas em economia e de representantes da elite cultural, bem como organizações humanitárias e as igrejas católica e protestante.

Sob diversas formas vai-se impondo a necessidade para a Alemanha de relacionar-se de uma nova maneira com a imigração (Wienholtz \& Holtschneider, 1998).

A intervenção dos representantes do mundo econômico altera, com uma rapidez surpreendente, o clima da opinião pública. No início de 2000 , o setor de informática e, logo a seguir outros setores da economia, alardeiam: há necessidade urgente de trabalhadores estrangeiros, de modo todo particular de 
técnicos especializados. Alguns comentários nos veículos de comunicação vêem nisso um primeiro sinal daquilo que será o futuro da Alemanha: um país em rápido processo de envelhecimento de sua população e que verá diminuir fortemente nas próximas décadas sua população economicamente ativa. Este dado vem, entre outro, confirmado por um estudo das Nações Unidas, a quem os meios de comunicação de massa dão grande importância (Meier-Braun, 2001: 59-68).

Os partidos, até o momento acostumados com uma política migratória muito cautelosa, vêem-se totalmente desprevenidos diante dessa repentina mudança do quadro, favorecida por uma conjuntura econômica positiva. A reação, de qualquer modo, não se faz esperar: são introduzidas as carteirinhas verdes (a exemplo dos EUA) para poder recrutar do exterior técnicos em informática. Sobretudo começa a se tornar mais consistente a hipótese da formulação da tão esperada nova lei da imigração. Para tanto, constitui-se uma comissão composta por políticos e especialistas para delinear os traços principais da política migratória necessária ao país. Finalmente, em 2001, o Ministro do Interior apresenta o projeto de lei. Nenhum partido pode, a partir disso, afirmar publicamente que a Alemanha "não é um país de imigração".

Porém, os atentados do 11 de setembro representam, sob este aspecto, uma nova cisão: retorna ao centro do debate a questão da segurança e a temática das diferenças culturais. Surge a interrogação se o islamismo, e em decorrência, os imigrantes muçulmanos podem representar um perigo para o país e para a ordem democrática. A estes problemas somam-se a crise da economia, o aumento do desemprego e a aproximação da campanha eleitoral do pleito de 2002. E neste clima novamente alterado, a CDU/CSU procura obter consensos através de uma crítica ferrenha à nova lei de imigração.
Nos anos 1999-2001 há um forte interesse da mídia para com o tema da imigração: duas são as imagens recorrentes: de um lado, os imigrantes como recurso econômico e demográfico necessário e, de outro, o estrangeiro como portador de diferenças étnicas, culturais e religiosas que em certo modo pode alterar a identidade do povo alemão (Jung, Niehr \& Böke, 2000). A imigração constitui um bem para o país quando é possível selecionar os imigrantes: jovens, profissionais altamente qualificados, aptos a se inserir na sociedade alemã por meio do aprendizado da língua. Ambas as imagens representam, mais uma vez, uma simplificação da realidade que a mídia assume e reproduz a partir, sobretudo, do debate político. O imigrante como recurso responde a reais necessidades econômicas e demográficas do país: é uma imagem enfim positiva, mas na realidade muito ambígua. A pessoa humana é considerada somente enquanto mão-deobra. Esta redução é perigosa, pois não leva em consideração os aspectos humanos, culturais, os problemas de integração e corre o risco de atrelar a presença dos imigrantes unicamente à conjuntura de uma economia em expansão. Semelhante postura constitui na prática um retrocesso à perspectiva do Gastarbeiter: ao trabalhadorhóspede, que atua somente no âmbito da produção, não existindo para os demais setores da sociedade e impossibilitado, como tal, de contribuir para mudanças significativas.

Contrapõe-se a isso, a outra imagem que acentua de modo todo particular os aspectos étnicos e culturais. Se, por um lado, a problemática da convivência entre as diferenças numa mesma sociedade não pode ser ignorada, por outro, nos meios de comunicação, este delicado tema é freqüentemente abordado com tons alarmistas ou através da utilização de expressões que reduzem o discurso a uma oposição entre "nós", "os alemães", enquanto realidade homogênea e unida por valores comuns e, "eles", "os turcos", "os estrangeiros", corpo estranho a ser assimilado lentamente. As simplificações neste âmbito, que constituem realmente o desafio do futuro, não só na Alemanha, mas em todo o mundo, impedem uma busca mais aprofundada de como gerir e vivenciar, na época da globalização, uma convivência entre culturas e mentalidades por vezes muito distantes entre si. Os meios de comunicação, às vezes, interpretam como conflitos étnicos aquilo que na verdade constitui problemas sociais difusos em meio à população imigrante e que poderiam ser facilmente resolvidos através de simples medidas políticas.

\section{Considerações finais}

Ao longo da década de 90 , os próprios responsáveis pela informação interrogam-se quanto à possibilidade de desenvolver formas mais adequadas para evitar, pelo menos em parte, na comunicação de massa, excessivas distorções no trato da realidade migratória (Predelli, 1995: 126-127). Historicamente, os países europeus caracterizaram-se pela co-presença de muitas culturas sobre um mesmo território, porém, nas últimas décadas, a imigração acentuou o processo de transformação em direção a sociedades pluriétnicas. $\mathrm{O}$ mundo da informação não pode permanecer, como de fato não permaneceu, insensível diante das mudanças que estão se verificando, deve porém, também assumir para si a responsabilidade de favorecer o encontro e o diálogo entre as diversidades, ao invés de dar maior visibilidade e até mesmo aguçar os problemas de convivência. Sob este prisma, os jornalistas, a imprensa, interessados com a informação de boa qualidade, deveriam considerar seriamente as estratégias, as estruturas e os critérios que determinam a escolha das notícias no que tange ao tema da imigração. 
Seria, por exemplo, recomendável a superação dos déficits com relação às contribuições positivas aportadas pelos imigrantes, através de uma maior atenção ao contexto das notícias. Sobretudo é importante oferecer uma imagem mais completa dos movimentos migratórios, divulgando não somente números dos que chegam, mas também analisando a situação dos países de origem e, portanto, as causas da emigração e da fuga (Hömberg \& Schlemmer, 1995). As migrações como fenômeno global não aparecem frequentemente na mídia.

Dever-se-ia prestar muita atenção à linguagem utilizada pelos meios de comunicação ao se referirem aos estrangeiros, evitando incorporar expressões depreciativas de uso corrente, bem como certas metáforas que podem acentuar, por exemplo, a idéia de invasão ou ameaça. Faz-se também necessária uma postura crítica na seleção das citações, principalmente das dos políticos, para evitar a instrumentalização. Quem escreve pode, de fato, distanciarse de maneira explícita daquilo que por dever do ofício noticia.

No âmbito da formação dos jornalistas aparece como sendo cada vez mais importante o aspecto da interculturalidade e do conhecimento do fenômeno migratório, o que permite a tomada de consciência quanto aos estereótipos e preconceitos que também os responsáveis pela informação, enquanto pessoas iguais às outras, herdam do próprio meio. Isso possibilitaria uma comunicação mais abalizada e objetiva das diversidades culturais presentes na sociedade. Seria desejável um conhecimento direto da vida das comunidades dos migrantes e das experiências pessoais, para poder apresentar os aspectos mais ordinários e cotidianos, bem como toda a riqueza humana que as pessoas carregam consigo.

Talvez o mais importante passo seria o de facilitar aos estrangeiros o acesso aos meios de comunicação. As redações não deveriam falar apenas deles, mas com eles e, na melhor das hipóteses, abrir espaço aos jornalistas de origem estrangeira. É sabido que as comunidades de imigrantes vêm utilizando cada vez mais os meios de comunicação alemã para a própria informação (Méier-Braun, 2001: 59-68). Esta possibilidade deveria ser favorecida para impedir a formação de "guetos" no campo da comunicação, tal como ocorre na transmissão direta em língua materna, em virtude da comunicação via satélite. A necessidade de favorecer a convivência pode transformar-se em oportunidade para que também o sistema jornalístico seja provocado - pelas transformações que estão acontecendo - a reconsiderar as próprias responsabilidades e a reavaliar os princípios mono-culturais e os critérios de divulgação da notícia que determinam o seu modo de produzir informação.

* Luisa Deponti é Missionária Secular Scalabriniana e do Centro de Estudos e Pesquisa sobre Emigração - CSERPE/ Basiléia.

\section{REFERÊNCIAS BIBLIOGRÁFICAS}

BADE, Klaus

(1994) Homo Migrans, Wanderungen aus und nach Deutschland, Klartext Verlag, Essen.

BADE, Klaus

(1995/1996) Vom Auswanderungsland ohne Auswanderungsgesetz zum

Einwanderungsland ohne

Einwanderungsgesetz: deutsche

Paradoxien im 19. und 20. Jahrhundert, in 40 Jahre 'Gastarbeiter' in Deutschland,

Nomos Verlagsgesellschaft, Baden Baden.

BARTELT, Dawid

(1993) Der Skalpjäger hat Fieber, in Medium, mãrz, pp. 33-38.

BECK, Marieluise (2001) Migrationsbericht der Ausländerbeauftragten im Auftrag der Bundesregierung, Berlino.

FIJALKOWSKI, Jürgen

(1996) Migration im Spannungsfeld von Wissenschaft und Politk, in Symposium "Vom 'Gastarbeiter' zum 'Einwanderer'?", Schader Stiftung, Darmstadt.

GEIBLER, Rainer
(1997) Hohe Ausländerkriminalität - ein Stammtischgerücht, in Caritas 98, nouember.

GERHARD, Ute

(1992) Wenn Flüchtlinge und Einwanderer zu „Asylantenfluten“ werden - zum Anteil des Mediendiskurses an rassistischen Pogromen, in Osnabrücker Beiträge zur Sprachtheorie, märz.

HAILBRONNER, Kay

(1997) Was kann ein Einwanderungsgesetz bewirken?, in Aus Politik und Zeitgeschichte, inserto del settimanale Das Parlament, 7/nouember.

HÖMBERG, Walter, SCHLEMMER, Sabine

(1995) Fremde als Objekt, in Media Perspektiven, januar.

JÄGER, Siegfried

(1993) Kritische Diskursanalyse. Eine Einführung, Duisburg.

JUNG, Matthias, NIEHR, Thomas, BÖKE, Karin (2000), Ausländer und Migranten im Spiegel der Presse, Westdeutscher Verlag, Wiesbaden.

MEIER-BRAUN, Karl-Heinz (1995) 40 Jahre "Gastarbeiter" und Ausländerpolitik in Deutschland, in Aus Politik und Zeitgeschichte, inserto del settimanale Das Parlament, 25/ougust.

MEIER-BRAUN, Karl-Heinz

(1995-1996) 40 Jahre "Gastarbeiter" in Deutschland. 4. Radioforum Ausländer bei uns, Nomos Verlagsgesellschaft, Baden Baden.

MEIER-BRAUN, Karl-Heinz

(2001) Nach wie vor "blinde Flecken". 50 Jahre "Migration und Massenmedien": Trotz Fortschritten besteht Nachholbedarf, in E. CURRLE, T. WUNDERLICH (Hrsg.), Deutschland - ein Einwanderungsland? Rückblick, Bilanz und neue Fragen, Lucius \& Lucius, Stuttgart.

MÜNZ, Rainer

(1998) Schily hat nicht recht, in Die Zeit, 19/nouember.

MÜNZ, Rainer

(1999) Teilhaber statt Zaungäste, in Zeitschrift für Kulturaustausch, märz.

PREDELLI, Ulirich

(1995) Wie fremd sind uns Fremde?, Vistas Verlag, Berlino.

SCHMALZ-JACOBSEN, Cornelia

(1995) Bericht der Beauftragten der Bundesregierung für Ausländerfragen über die Lage der Ausländer in der Bundesrepublik Deutschland, Bonn.

WICHERT, Franz

(1997) Die Produktion rassistischer Effekte im Mediendiskurs, testo di una conferenza tenuta presso la Caritas di Stoccarda.

WIENHOLTZ, E., HOLTSCHNEIDER, R.

(1998) Wie die Ausländer zum Wohlstand in Deutschland beitragen, in Frankfurter Rundschau, 19/ougust. 